\title{
Short-term and Long-term Efficacy of Oropharyngolaryngeal Strengthening Training on Voice Using a Mobile Healthcare Application in Elderly Women
}

\author{
Nam-Bin Cho ${ }^{a}$, Sung-Rae $\mathrm{Cho}^{\mathrm{b}}$, Seong Hee Choi ${ }^{\mathrm{c}}$, Heecheon You ${ }^{\mathrm{d}}$, Seok In Name, HyangHee Kim ${ }^{\mathrm{a}, \mathrm{b}}$ \\ ${ }^{a}$ Graduate Program in Speech and Language Pathology, Yonsei University, Seoul, Korea \\ ${ }^{b}$ Department and Research Institute of Rehabilitation Medicine, Yonsei University College of Medicine, Seoul, Korea \\ 'Department of Audiology \& Speech-Language Pathology, Institute of Biomimetic Sensory Control, and Catholic Hearing Voice Speech Center, \\ Daegu Catholic University, Gyeongsan, Korea \\ ${ }^{d}$ Department of Industrial \& Management Engineering, Pohang University of Science and Technology, Pohang, Korea \\ ${ }^{e}$ Graduate School of Social Welfare, Yonsei University, Seoul, Korea
}

Correspondence: HyangHee Kim, PhD, CCC-SLP, BC-ANCDS

Graduate Program in Speech and Language,

Yonsei University College of Medicine, 11-12

Yeondaedongmun-gil, Seodaemun-gu, Seoul 03721, Korea

Tel: +82-2-2228-3900

Fax: +82-2-2227-7984

E-mail: h.kim@yonsei.ac.kr

Received: January 20, 2021

Revised: February 5, 2021

Accepted: February 5, 2021

This research was supported by National R\&D Program through the National Research Foundation of Korea (NRF) funded by Ministry of Science and ICT (2020M3C1B6113677, 2020M3C1B6113680)

This article is based on the Master's thesis of the first author, and a part of the content has been accepted by the Program Committee for the 2020 ASHA Convention, San Diego, CA, USA.
Objectives: A decline in vocal function due to aging interferes with successful communication in daily life, and negatively affects the quality of life. As part of an appropriate intervention for presbyphonia, adherence to regular voice exercise benefits and improves therapeutic effectiveness. The purpose of this study was to investigate the efficacy of oral and pharyngolaryngeal strength training on voice using a mobile healthcare application in elderly women. Methods: Eleven participants performed 'A Successful Swallowing with Effortful Training (ASSET)' at home for eight weeks using a mobile health application. A significant training effect was identified in seven participants ( 7 women, mean age $=74.6 \pm 5.7$ years) who performed the protocol appropriately. The effects of the training were measured by voice function evaluation and voice-related questionnaire assessment. Results: The post-training results showed significant increases in maximum phonation time, average fundamental frequency, and cepstral peak prominence smoothed, and significant decreases in jitter local, shimmer local, and noise to harmonic ratio (NHR) $(p<.05)$. Furthermore, a significant improvement was observed in the participants' voice-related quality of life. The long-term post-intervention evaluation showed that the improvement of NHR observed in the short-term efficacy was maintained for 12-weeks post-intervention $(p<.05)$. Conclusion: After the oral and pharyngolaryngeal strengthening training using a mobile application, voice function and voice-related quality of life in elderly women were improved and the improvement of voice function was maintained in the long term follow-up. This training protocol can be of use as an effective voice therapy for presbyphonia.

Keywords: Aging, Presbyphonia, Oral and pharyngolaryngeal strengthening training, Mobile healthcare app
노화가 진행됨에 따라 성대는 점차 경직되어 갑상피열근의 근위 축과 궁형성대(vocal fold bowing)를 초래한다(Rapoport, Menier, \& Grant, 2018). 성대를 포함한 후두 구조의 변화는 불완전 성문 폐 쇄, 기류 누출, 성대의 근긴장 저하 등으로 이어져 노년층의 음도, 음
량, 음질 등과 관련된 음성 기능을 저하시킨다(Bradley, Hapner, \& Johns III, 2014). 또한 노화에 따른 성호르몬의 감소도 음성 기능의 저하를 야기할 수 있는데, 노년 여성의 경우 성호르몬의 감소로 인 하여 음도가 낮아지는 경향이 있다(Pontes, Brasolotto, \& Behlau, 
Nam-Bin Cho, et al. • Efficacy of Oropharyngolaryngeal Strength Training on Voice Using mHealth App

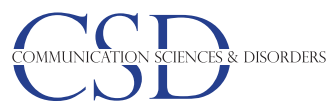

2005).

이와 같이 노화에 따른 후두 구조의 생리적 변화로 인한 음성 기 능의 저하, 즉 노화 음성(aging voice)을 노인성 음성장애(presbyphonia)라고 한다(Rosow \& Pan, 2019). 노인성 음성장애의 유병률 은 4.8-29.1\%이며, 최대연장발성시간(maximum phonation time, $\mathrm{MPT})$ 의 감소, 기본 주파수의 변화, 음도 범위 및 음량 감소, 목쉰 소리, 음성의 불안정, 기식성 및 긴장성의 증가, 진전(tremulousness), 음성 피로, 말할 때의 흡인(aspiration) 등이 그 특징이다(Pessin, Tavares, Gramuglia, de Carvalho, \& Martins, 2017; Pontes et al., 2005). 노년층의 음성 문제는 신체적, 감정적, 기능적, 사회적 측 면의 삶의 질에 부정적 영향을 미치며 의사소통, 일상생활, 사회적 참여를 방해하므로 노인성 음성장애에 대한 중재가 필요하다(Etter et al., 2019).

노년층의 음성 기능과 삶의 질 향상을 위한 음성치료의 수요는 크게 증가하고 있으며 노년층의 대다수는 음성치료를 통해 음성 문 제와 삶의 질을 개선할 수 있다고 믿는다(Takano et al., 2010). 실제 로 노인성 음성장애를 대상으로 한 행동적 음성치료는 음성 문제 개선에 효과적이며 궁형성대의 휨 정도를 감소시킬 수 있다 $(\mathrm{Go}-$ doy, Silverio, \& Brasolotto, 2019). 노인성 음성장애를 대상으로 음 성 문제 개선을 확인한 치료법으로는 리실버만 음성치료(Lee Silverman Voice Treatment, LSVT), 성대기능훈련(vocal function exercise, VFE), 발성 저항 훈련(phonation resistance training exercises, PhoRTE), 노년층을 위한 음성치료(Vocal Therapy for the Elderly, VTE), 성대 에어로빅 치료(vocal aerobic treatment, VAT) 등 이 있다(Godoy et al., 2019; Kaneko et al., 2015; Kang \& Yoo, 2019; Lu, Presley, \& Lammers, 2013; Ziegler, Verdolini Abbott, Johns, Klein, \& Hapner, 2014). 그러나 사례연구로 이루어져 통계적 검증 을 하지 않았거나(Kang \& Yoo, 2019; Lu et al., 2013), 주관적인 측 정치(예, V-RQOL)로 효과를 확인한 연구(Godoy et al., 2019; Ziegler et al., 2014)를 제외하면 객관적인 측정치(예, 음향학적 지 표)로 효과가 검증된 노인성 음성장애의 행동적 음성치료 방법은 상대적으로 부족한 실정이다.

또한 기존의 음성치료는 임상가와의 대면 치료를 원칙으로 하는 데 노년층의 경우 거리, 이동 시간, 대기 시간, 비용과같은 접근성 문 제로 인하여 병원에서 이루어지는 대면 치료에 지속적으로 참여하 는 것은 어려움이 있을 수 있다(Griffin, Bentley, Shanks, \& Wood, 2018). 접근성의 제한은 치료의 참석률을 저하시키고 결국 노년층 의 음성 문제 개선에 부정적 영향을 미치므로 접근성 문제의 해결 은 노인성 음성장애 치료 시 필수적으로 고려해야 할 사항이다 $(\mathrm{Fu}$, Theodoros, \& Ward, 2015). 의료 접근성 문제는 모바일 헬스케어를
통해 해결할수 있는데 모바일 헬스케어는 의료 서비스를 디지털 시 대에 도입할 수 있는 잠재력을 가지고 있으며 이를 통해 자가 건강관 리를 용이하게 한다. 노년층이 모바일 헬스케어를 수용하고 사용한 다면 건강 지원 이외에도 시간 및 의료비 관리 측면에서 도움이 될 수 있다(Bene et al., 2019).

'365 삼킴 건강 코치(365 Healthy Swallowing Coach)'는 노년층 삼킴 문제의 예방 및 재활을 위한 중재 프로그램을 주 콘텐츠로 개 발된 앱이다(Kim, Lee et al., 2020). 이 앱의 삼킴 훈련 콘텐츠에서 사용된 훈련법인 'ASSET(A Successful Swallowing with Effortful Training)'은 노력 삼킴(effortful swallow)과 멘델슨 기법(Mendelsohn maneuver)을 융합한 힘껏 오래 삼키기(effortful prolonged swallow, EPS), 힘껏 음도 높이기(effortful pitch glide, EPG), 힘껏 혀 돌리기(effortful tongue rotation, ETR)로 구성되어 있으며 구강 및 인후두의 근력 강화를 목표로 한다(Arakawa, Koide, Takahashi, \& Mizuhashi, 2015; Kim, Cho et al., 2020; Mendelsohn \& McConnel, 1987; Miloro, Pearson Jr, \& Langmore, 2014; Pouderoux \& Kahrilas, 1995). ASSET의 일차적 목표는 삼킴 기능의 향 상이지만 음성 기능의 개선에도 효과적일 수 있다. 신경 가소성 (neural plasticity)의 전이(transference) 원칙에 의하면 한 종류의 기능 개선은 유사한 다른 기능의 획득을 촉진할 수 있으므로 특정 기능의 향상에 초점을 둔 치료는 교차 계통(cross-system) 효과를 이용해 다른 기능의 향상에도 영향을 미칠 수 있다(Kleim \& Jones, 2008). 음성과 삼킴은 구강, 인두, 후두, 호흡 근육의 정밀한 통합을 요구하는 복잡한 협응 체계로 신경분포, 구조, 근조직과 같은 해부 학적, 신경생리학적 요소를 공유한다(Fujiki, Oliver, Sivasankar, Craig, \& Malandraki, 2019). 예를 들어 성문 폐쇄는 음성 산출에 필수적이며 동시에 삼킴 시 기도를 보호하는 역할을 하고 설골-후 두 상승(hyo-laryngeal excursion)은 기도 폐쇄를 유발하여 음식덩 이가 침습(penetration) 또는 흡인 되는 것을 방지할 뿐만 아니라 음 도 상승에 기여한다(Fujiki et al., 2019). 따라서 음성 기능의 저하는 삼킴 기능에도 영향을 미칠 수 있으며 반대로 삼킴 기능의 저하는 음성 기능에도 영향을 미칠 수 있다. 앞서 언급한 바와 같이 노인성 음성장애의 음성 특징 중 하나는 성대의 휨에 따른 기식성 증가이 다. ASSET의 EPG와 EPS는 성문 폐쇄 증가에 직간접적으로 긍정 적인 영향을 미치며(Godoy et al., 2019; Inamoto et al., 2018), 이는 노년층의 음성 문제 개선에 효과적일 수 있다. 이에 본 연구에서는 노년층을 대상으로 모바일 애플리케이션을 이용한 구강 및 인후두 근력 운동(EPS, EPG, ETR)을 8주 동안 실시하게 하여 음성 측면에 서의 개선 및 유지 효능을 확인하고자 한다. 


\section{연구방법}

\section{연구대상}

본 연구는 한국연구재단의 '과학기술인문사회융합연구사업(과 학기술정보통신부 주관)'의 일환으로 진행되었으며 연세대학교 대 학원 언어병리학협동과정과 포항공과대학교 산업경영공학과와의 융합연구이다. 대상자 모집은 2019년 11월에 두 군데의 서울 소재 노인종합복지관에서 네 번에 걸쳐 진행되었다. 선정 기준은 1) 만 65 세 이상인 자, 2) 음성 또는 삼킴 문제를 보고한 자, 3) 한국판 간 이 정신상태 검사(Korean-Mini Mental State Examination, KMMSE; Kang, 2006) 점수가 연령 및 교육수준별 규준에서 정상 범 주에 속해 인지 기능에 문제가 없는 자, 4) 시각, 청각, 상지 운동기 능 상에 문제가 없어 태블릿을 사용할 수 있는 자이다. 제외 기준은 1) 신경학적 질환으로 진단받은 자, 2) 코위영양관(nasogastric tube), 경피적내시경위조루술(percutaneous endoscopic gastrostomy) 등 비구강 섭식(non-oral feeding) 중인 자, 3) 성대결절, 성대낭종, 성 대마비 등의 음성장애로 인한 음성 기능의 저하를 보고한 자이다.

본 연구 대상자는 Kim, Cho et al. (2020)과 Kim, Lee et al. (2020) 연구에 참여한 동일한 참가자들이다. 총 11 명의 대상자가 본 연구 에 참여하였으나, 이 중 3 명이 훈련 프로토콜을 미순응하였고 1 명 이 감기로 인해 음성 기능이 저하되어 7명(여성 7명)을 대상으로 결 과를 분석하였다. 7 명의 평균 연령은 $74.6 \pm 5.7$ 세, 평균 교육년수는 $10.9 \pm 3.2$ 년이었으며, K-MMSE의 평균 점수는 $28.1 \pm 2.1$ 점이었다. 본 연구는 생명윤리위원회(Institutional Review Board, No. PIEB2019-E024)의 승인을 받았다.

\section{구강 및 인후두 근력 강화 훈련}

\section{훈련 프로토콜}

구강 및 인후두 근력 강화 훈련 프로토콜의 1 회기 구성은 ASSET 의 각 훈련법(EPS, EPG, ETR)을 20 회씩 반복하는 것으로 약 20 분 이 소요된다. 대상자는 8 주 동안(주 5 회, 일 3 회) 가정에서 총 120 회 기의 훈련을 앱을 이용하여 진행하였다. 훈련법의 세부 절차는 본 연구진에 의해 이루어진 선행연구에 제시된 바와 같다(Kim, Cho et al., 2020).

\section{훈련 도구}

일반적으로 노년층은 테크놀로지에 익숙하지 않으며 신체적, 인 지적 장벽에 직면한다(Wildenbos, Jaspers, Schijven, \& DusseljeePeute, 2019). 그러나 모바일 헬스케어로부터 건강 지원 혜택을 얻 기 위해서는 스마트 기기의 다양한 기능들을 숙지할 필요가 있다.
365 삼킴 건강 코치는 노년층의 특성을 고려하여 모바일 앱에 대한 친숙도와 관계없이 간단하게 사용할 수 있도록 고안되었다(Kim, Lee et al., 2020). 노년층을 위한 사용자 인터페이스 설계의 예로는 탐색(navigation)의 용이성을 위해 사용 순서(use-sequence)대로 배열된 탭, 이해의 용이성을 위해 아이콘과 텍스트를 모두 포함한 버튼 등이 있다(Kim, Cho et al., 2020). 365 삼킴 건강 코치는 프로 토타입 단계로 안드로이드 운영 체제(Android operating system, version 8.1.0)의 갤럭시 탭 A SM-P580 (Samsung Electronics Co., Ltd., Seoul, Korea)에서만 호환되었다. 대상자는 365 삼킴 건강 코 치의 삼킴 훈련 콘텐츠를 이용하여 구강 및 인후두 근력 강화 훈련 을 실시하였다. 삼킴 훈련 콘텐츠의 개요도는 Figure 1과 같다.

\section{교육 및 점검}

프로그램 시작 전 연구자 2 명 $(1$ 급 언어재활사 1 명, 2 급 언어재활 사 1 명)은 대상자에게 앱 조작법과 훈련법을 교육하였다. 훈련 개시 후 연구자는 격주마다 대상자와 대면하여 앱 조작법, 훈련법, 훈련 수행률 등을 점검하였다. 단, 본 연구의 점검 목적은 대상자가 외적 도움 없이도 스스로 앱을 조작하여 훈련할 수 있는 능력을 확인하 기 위함이므로 그들의 자가 훈련 수행에 직접적인 영향을 미칠 수 있는 개입을 최소화하였다. 대면 점검 시 대상자는 앱을 탐색하여 삼킴 훈련 콘텐츠 화면으로 이동한 후 1 회기 훈련을 실시하였으며 연구자는 이 과정을 감독하되 대상자가 앱을 조작하지 못하거나 부적절한 방법으로 훈련하는 경우에만 일부 개입하였다. 대면 점검 은 개인별로 진행하였으며 약 30 분간 진행되었다.

\section{치료 순응}

대상자가 훈련을 마치고 앱을 종료하면 연구자들은 태블릿에 저 장된 데이터베이스를 추출하여 훈련 수행률을 확인하였다. 수행률 은 추출된 데이터베이스를 CSV (comma separated values) 파일로 변환한 후 Excel (Microsoft Corp., Washington D.C., USA, version 2016) 프로그램을 통해 산출하였다. 본 연구에서는 훈련 프로토콜 의 치료 순응(adherence) 기준을 80-120\%의 수행률로 선정하였다.

\section{자료수집 및 분석}

구강 및 인후두 근력 강화 훈련 이전에 사전 평가를 실시하였으 며 훈련 종료 직후와 종료 12 주 후에 각각 사후 평가와추적 평가를 실시하였다. 평가 절차는 음성 기능 평가, 음성 관련 설문 평가 순으 로 진행하였다. 단기 효능은 훈련 프로토콜을 적합하게 수행한 7명 을 대상으로 이루어졌으며, 장기 효능은 7명 중 추적 평가 참여에 동의한 5 명을 대상으로 이루어졌다. 


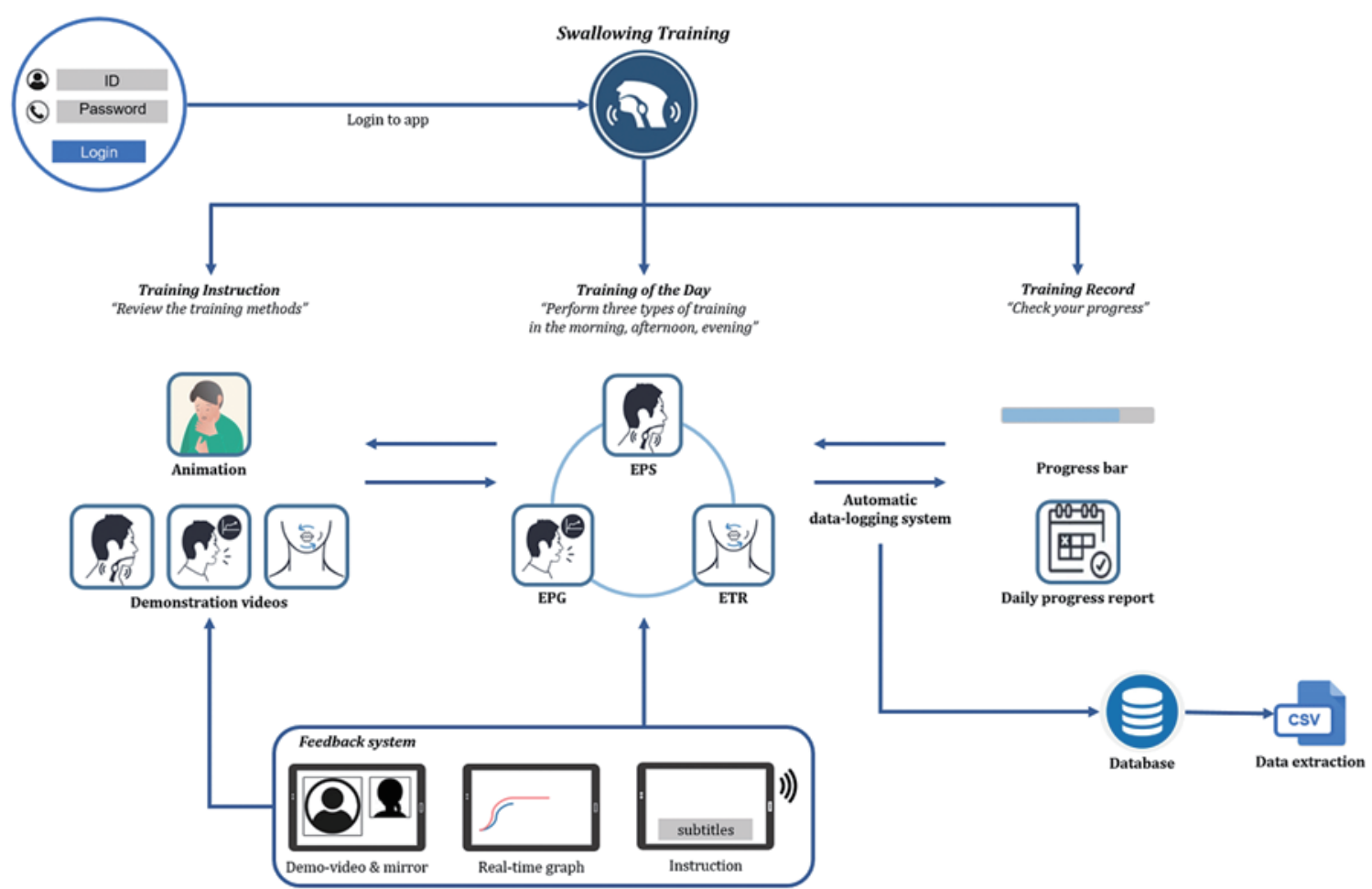

Figure 1. Overview of 365 Healthy Swallowing Coach app.

EPS = effortful prolonged swallow; EPG = effortful pitch glide; ETR=effortful tongue rotation. This figure is licensed under a Creative Commons Attribution (CC-BY) 4.0 license (source: Kim, Lee et al. (2020), https://mhealth.jmir.org/2020/10/e19585/).

\section{음성 기능 평가}

모든 음성 및 말 자료는 환경 소음 $50 \mathrm{~dB}$ 이하의 연구실에서 수 집하였다. 대상자는 의자에 앉아 편안한 자세를 취하고 입과 마이 크와의 거리는 $10 \mathrm{~cm}$ 로 유지하였다. 이후 90 도 각도로 고정된 콘덴 서 마이크 SONY ECM-MS907 (SONY Corp., Tokyo, Japan)을 이 용하여 녹음기 SONY ICD-UX560F (SONY Corp., Tokyo, Japan) 에 녹음하였다. 녹음 시 표본 추출률(sampling rate)은 $44,100 \mathrm{~Hz}$, 양자화(quantization)는 16 bit로 하였다. 수집한 음성 자료는 Praat (Institute for Phonetic Sciences, University of Amsterdam, The Netherlands, Windows 64-bit edition, version 6.1.16)을 이용하여 분석하였다(Boersma \& Weenink, 2011). 본 연구에서 음성 기능 평 가는 모음 $/ \mathrm{a} /$ 최대연장발성, 모음 $/ \mathrm{a} / 5$ 초 연장발성, 문단 읽기를 통 해 이루어졌다.

모음 /a/ 최대연장발성은 최대한 깊게 숨을 들이 마신 후 편안한 음도 및 음량으로 모음 $/ \mathrm{a} /$ 를 최대한 길게 발성하도록 하였으며 3 회 중 가장 우수한 수행을 자료로 선택하였다. MPT는 발성 기제(mechanism)뿐만 아니라 발성 동안의 호흡 기제의 효율성을 비침습적으 로 빠르게 확인할 수 있는 객관적인 측정치이다(Dejonckere, 2010). 모음 /a/ 5 초 연장발성은 최대한 깊게 숨을 들이 마신 후 편안한
음도 및 음량으로 모음 /a/를 5 초 동안 발성하도록 하였으며 대상자 의 음성 특성을 최대한 반영하기 위해 모음 /a/ 연장발성 자료의 발 성 시작 후 0.25 초와 발성 종료 전 0.25 초를 제외한 후 가장 안정된 3 초 구간을 분석하였다. 3 초는 대부분의 음향학적 지표를 신뢰성 있게 분석하기에 충분하다(Kent, Vorperian, Kent, \& Duffy, 2003). 모음 /a/ 5 초 연장발성 자료의 음향학적 지표 분석은 Kent 등(2003) 의 음향학적 음성 분석 권고사항을 준수하였다. 모음 /a/ 5 초 연장 발성 자료에서 분석한 변동률 분석 지표는 기본 주파수 관련 지표 인 평균 기본 주파수(average fundamental frequency, F0), 기본 주 파수 표준편차(standard deviation of fundamental frequency, F0SD), 주파수변동률(jitter local, Jitter), 진폭변동률(shimmer local, Shimmer) 소음대배음비(noise to harmonic ratio, NHR)이다.

문단 읽기는 '가을' $(\mathrm{Kim}, 1996)$ 을 1 회 읽도록 하였다. 문단 읽기 자료의 음향학적 지표 분석은 미국언어청각협회(American Speech-Language-Hearing Association, ASHA)에서 권고한 음향 학적 음성 분석 프로토콜(Patel et al., 2018)을 준수하였다. 가을 문 단 분석 범위는 두 번째 문장 ‘무엇보다도 산에 오를 땐 더욱 더 그 빼어난 아름다움이 느껴진다.로 선정하였다. 가을 문단 읽기 자료 를 이용한 스펙트럼 및 켑스트럼 분석은 음성장애 유무를 선별하 
는 데 있어 유용한 수단이 될 수 있으며 이는 두 번째 문장만으로도 가능하다(Lee, Lim, \& Choi, 2017). 가을 문단 읽기 자료에서 분석 한 지표는 기본 주파수 관련 지표인 평균 발화 기본 주파수(speaking fundamental frequency, sF0), 발화 기본 주파수의 표준편차 (standard deviation of speaking fundamental frequency, sF0SD), 평활화된 켑스트럼 피크 현저성(cepstral peak prominence smoothed, $\mathrm{CPPs}$ )이다. $\mathrm{CPPs}$ 분석 시에는 Time averaging window는 0.02 초, Quefrequency averaging window는 0.0005초, Peak search pitch range는 60-330 Hz, Tolerance는 0.05, Interpolation은 Parabolic, Trend line quefrency range는 0.001-0.050초, Trend type은 Exponential decay, Fit method는 Robust slow로 설정하였다.

\section{음성 관련 삶의 질 평가}

VHI-10 (Voice Handicap Index-10)은 대상자가 주관적으로 느 끼는 음성 문제의 정도를 측정할 수 있는 10 문항의 음성 기능 자가 보고 설문 평가이다(Rosen, Lee, Osborne, Zullo, \& Murry, 2004). 국내에서도 이를 번안한 한국어판 VHI-10이 개발되어 그 타당도 와 신뢰도가 입증되었다(Yun, Kim, Son, \& Choi, 2008). 본 설문은 사전, 사후에만 실시되었으며, 대상자가 일상생활에서 느끼는 음성 문제의 자가 인식 정도를 확인하기 위하여 VHI-10을 실시한 후 총 점수를 산출하였다.

\section{통계분석}

사전, 사후, 추적 평가에 대한 통계는 IBM SPSS (Statistical Pack- age for the Social Science, version 25.0) for Window 프로그램을 사용하여 분석하였다. 첫째, 8주 동안의 앱을 이용한 구강 및 인후 두 근력 강화 훈련 후 노년층의 음성 기능 및 음성 관련 삶의 질이 개선되었는지를 확인하기 위해 사전 평가와사후 평가 자료에 대해 윌콕슨 부호 순위 검정을 실시하였다. 둘째, 프로그램 직후 개선된 음성 기능이 12 주 후에도 유지되고 있는지를 확인하기 위해 우선 사전 평가와 사후 평가에서 유의한 변화가 확인된 변인을 대상으 로 프리드만 검정을 실시하여 사전, 사후, 추적 평가 세 시점 간 수 치적으로 유의한 변화가 있었는지를 확인하였다. 이후 프리드만 검 정에서 유의한 변화가 확인된 변인을 대상으로 사전 평가와 추적 평가 자료에 대해 윌콕슨 부호 순위 검정을 실시하였다.

\section{연구결과}

\section{음성 기능}

구강 및 인후두 근력 강화 훈련 후 $\mathrm{MPT}, \mathrm{F} 0, \mathrm{CPPs}$ 는 훈련 전에 비하여 유의하게 증가하였고 $(p<.05)$, Jitter, Shimmer, NHR은 유 의하게 감소하였다 $(p<.05)$. 한편 $\mathrm{F} 0 \mathrm{SD}, \mathrm{sF} 0, \mathrm{sF} 0 \mathrm{SD}$ 는 훈련 전후 유 의한 변화가 없었다(Table 1). 훈련 후 유의한 변화가 나타난 음향학 적 지표 중 Jitter, NHR이 사전, 사후, 추적 평가의 세 시점 간 유의 한 변화가 나타난 반면( $p<.05), \mathrm{MPT}, \mathrm{F} 0$, Shimmer, CPPs는 유의 한 변화가 없었다(Table 2). 훈련 종료 12주 후 NHR은 훈련 전에 비 하여 유의하게 감소하였으나 $(p<.05)$, Jitter는 유의한 변화가 없었 다(Table 3). 즉 훈련 직후 MPT, F0, Jitter, Shimmer, NHR, CPPs가

Table 1. Acoustic measures in pre- and post-training ( $\mathrm{N}=7)$

\begin{tabular}{lccc}
\hline Variable & Pre-training & Post-training & $p$ \\
\hline Maximum vowel /a/ phonation & $10.59(9.54,13.67)$ & $14.08(13.70,23.94)$ & $.018^{*}$ \\
MPT & & & \\
Vowel /a/ 5 second phonation & $154.3(135.3,191.7)$ & $198.1(167.6,206.9)$ & $.028^{*}$ \\
F0 (Hz) & $1.92(1.47,2.56)$ & $1.53(1.29,1.76)$ & .063 \\
FOSD (Hz) & $.387(.298,676)$ & $.225(.166, .244)$ & $.018^{*}$ \\
Jitter (\%) & $4.111(1.904,6.731)$ & $2.026(1.589,2.238)$ & $.028^{*}$ \\
Shimmer (\%) & $.019(.007, .050)$ & $.004(.004, .011)$ & $.018^{*}$ \\
NHR & & & \\
Passage reading & $165.5(160.9,180.5)$ & $172.9(164.3,182.7)$ & .091 \\
SFO (Hz) & $27.81(25.10,31.97)$ & .499 \\
SFOSD (Hz) & $10.24(8.82,10.48)$ & $27.58(20.00,32.51)$ & $.043^{*}$ \\
CPPs (dB) & $10.67(9.67,11.12)$ & \\
\hline
\end{tabular}

Value are presented as median (1 quartile, 4 quartile).

$\mathrm{MPT}=$ maximum phonation time; FO= average fundamental frequency; FOSD=standard deviation of fundamental frequency; Jitter=jitter local; Shimmer=shimmer local; $\mathrm{NHR}=$ noise to harmonic ratio; $\mathrm{SFO}=$ speaking fundamental frequency; $\mathrm{SFOSD}=$ standard deviation of speech fundamental frequency; $\mathrm{CPPS}=\mathrm{cepstral}$ peak prominence smoothed.

${ }^{*} p<.05$. 
Table 2. Acoustic measures in pre-, post-training and follow-up ( $N=5)$

\begin{tabular}{lcccc}
\hline Variable & Pre-training & Post-training & Follow-up & $p$ \\
\hline Maximum vowel /a/ phonation & & & & \\
$\quad$ MPT & $10.10(8.40,12.13)$ & $14.01(13.26,24.51)$ & $16.33(10.81,26.90)$ & .091 \\
Vowel /a/ 5 second phonation & $138.0(132.0,194.9)$ & $198.1(151.5,217.3)$ & $192.8(147.3,216.8)$ & .449 \\
FO $(\mathrm{Hz})$ & $.387(.326, .734)$ & $.225(.194, .283)$ & $.328(.235, .423)$ & $.041^{*}$ \\
Jitter (\%) & $4.372(2.021,8.235)$ & $2.026(1.428,2.189)$ & $2.888(1.819,3.540)$ & .074 \\
Shimmer (\%) & $.033(.007, .091)$ & $.004(.004, .008)$ & $.007(0.004, .020)$ & $.015^{*}$ \\
NHR & & & & \\
Passage reading & $10.45(9.19,11.33)$ & $10.67(9.51,11.98)$ & $10.01(8.61,10.60)$ & .165 \\
CPPs & & & \\
\hline
\end{tabular}

Value are presented as median (1 quartile, 4 quartile).

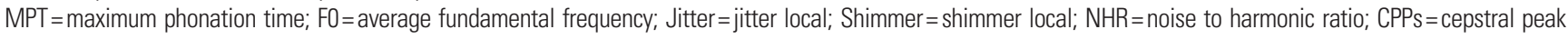
prominence smoothed.

${ }^{*} p<.05$.

Table 3. Acoustic measurement in pre-training and follow-up ( $N=5)$

\begin{tabular}{lccc}
\hline Variable & Pre-training & Follow-up & $p$ \\
\hline Vowel /a/ 5 second phonation & & & \\
Jitter $(\%)$ & $.387(.326, .734)$ & $.328(.235, .423)$ & .138 \\
NHR & $.033(.007, .091)$ & $.007(.004, .020)$ & $.043^{*}$ \\
\hline
\end{tabular}

Value are presented as median (1 quartile, 4 quartile). Jitter=jitter local; NHR=noise to harmonic ratio. ${ }^{*} p<.05$.

개선되었으며, 이 중 NHR의 개선이 훈련 종료 12 주 후까지 유지되 고 있었다.

\section{음성 관련 삶의 질}

구강 및 인후두 근력 강화 훈련 후 VHI-10 총점(중위수 $=0,1$ 사 분위수 $=0,4$ 사분위수 $=1)$ 이 훈련 전(중위수 $=2,1$ 사분위수 $=2,4$ 사분위수 $=5)$ 에 비하여 유의하게 낮았다 $(p=.025)$. 즉 훈련 직후 음성 관련 삶의 질이 개선되었다.

\section{논의 및 결론}

노화로 인해 저하된 음성 기능은 노년층의 의사소통, 일상생활, 사회적 참여 등을 방해하며 삶의 질에 부정적 영향을 미치므로 노 인성 음성장애에 대한 중재가 필요하다. 고강도의 구강 및 인후두 근력 강화 훈련은 음성 산출에 관여하는 근육을 강화하여 노년층 의 음성 기능을 향상시킬 수 있다. 이때 훈련 효과를 최대화하기 위 해서는 노년층의 훈련 순응이 필수적이며 모바일 헬스케어는 훈련 순응도를 높이는 데 효과적인 수단이 될 수 있다. 이에 본 연구는 7 명의 노년층을 대상으로 모바일 헬스케어 애플리케이션을 이용한
구강 및 인후두 근력 강화 훈련이 음성에 미치는 장단기 효능을 확 인하였다. 본 연구 결과를 일곱 가지 측면에서 고찰한 사항은 다음 과 같다.

첫째, 훈련 후 MPT가 유의하게 증가하였다. EPG와 같이 소리를 강하게 산출하고 이를 최대한 유지하는 훈련법은 호기근을 강화하 고 성대의 내전 정도를 증가시킬 수 있다(Lu et al., 2013). 노년층을 대상으로 한 선행연구 역시 음도 높이기 과제가 포함된 총체적 음 성치료(예, LSVT, VFE) 후 MPT가 유의하게 증가하였다(Gorman,

Weinrich, Lee, \& Stemple, 2008; Lu et al., 2013). 주목할 만한 점은 다양한 발성 기법으로 구성된 총체적 음성치료와 달리 ASSET은 하나의 발성 기법만 다루지만 선행연구와 동일한 결과가 나타났다 는 것이다. 이는 $\mathrm{EPG}$ 를 실시하는 동안 발성을 최대한 유지하였기 때문이었을 것이다. 노년층을 대상으로 호흡근 강화 훈련을 가미한 음성치료를 실시한 선행연구 결과, 훈련 후 최대 호기력이 증가하였 다(Desjardins, Halstead, Simpson, Flume, \& Bonilha, 2020). EPG 도 발성을 최대한 오래 유지해야 할 뿐만 아니라 음높이가 올라갈 수록 더 큰 성문하압이 요구되므로 이는 호흡근 강화 훈련에 해당 될 수 있다. 즉 $\mathrm{EPG}$ 는 호흡 및 발성 기능 강화에 긍정적 영향을 미 쳤을 것이며 이를 통해 MPT가 증가하였을 것이다.

또한 EPS도 MPT 증가에 영향을 미쳤을 수 있다. 삼킴 훈련을 통 해 MPT가 증가했다는 선행연구는 없으나 밀기법(pushing meth$\mathrm{od}$ 과 같이 의도적으로 성문 폐쇄 지속시간을 증가시키는 동작을 가미한 훈련법은 노화로 인해 휘어지거나 위축된 성대의 내전을 도 모하여 음성 효율을 증가시킬 수 있다(Fujimaki et al., 2017). EPS를 실시하는 동안 구강 및 인후두 근육은 강하게 수축하며 이 수축은 일정시간 동안 유지된다. 이는 밀기 동작과 같이 의도적으로 성문 폐쇄 지속시간을 증가시키므로 음성 효율 및 $\mathrm{MPT}$ 증가에 영향을 
미쳤을 수 있다.

둘째, 훈련 후 노년 여성의 기본 주파수가 유의하게 높아졌다. 폐 경 이후 노년 여성의 후두 및 성대의 변화는 부종(edema), 쉰 목소 리, 성대의 경직, 음성피로, 고음 도달하기의 어려움으로 이어진다 (Hari Kumar, Garg, Ajai Chandra, Singh, \& Datta, 2016). 본 연구 에서는 훈련 후 기본 주파수가 유의하게 상승하였는데, 이는 EPG 가 기본 주파수 범위를 확장시키고 성대의 스트레칭과 유연성을 증 가시켜 성대 진동을 촉진시키는 데 도움을 준 것으로 여겨진다. 실 제로 노년층을 대상으로 한 선행연구 역시 음도 높이기 과제가 포 함된 총체적 음성치료 후 기본 주파수가 유의하게 증가하였다(Fabron et al., 2018; Lu et al., 2013).

한편 노화에 따른 음도 변화는 후두의 위치와 연관될 수 있다. 노 화가 진행됨에 따라 후두의 위치는 하강하며 이는 음도의 저하로 이어진다(Honda, Hirai, Masaki, \& Shimada, 1999). ASSET의 각 훈련법은 설골-후두 상승에 관여하는 근육을 강화하여 후두의 위 치를 상승시킬 수 있다. EPS는 일반적인 삼킴 시보다 설골-후두 상 승의 범위가 크며 최대 상승이 일정시간 동안 유지된다(Inamoto et al., 2018). ETR은 혀를 잇몸볼주름(gingivobuccal fold)에 내밀어 회전하는 훈련법으로 혀를 내미는 동안 설골-후두 상승에 관여하 는 설골상근이 수축한다(Arakawa et al., 2015). EPG는 일반적인 삼킴 시보다는 설골-후두 상승의 범위가 작지만(Kennedy, Pisegna, Kim, Parker, \& Langmore, 2020), EPG를 실시하는 동안 설골후두 상승에 관여하는 설골상근 및 종단인두근이 활성화된다 (Miloro et al., 2014). 설골-후두 상승의 범위를 강화하는 훈련을 통 해 노년 여성의 기본 주파수 변화 여부를 확인한 선행연구는 없으 나, ASSET의 세 가지 훈련이 후두 상승에 관여하는 근육을 강화하 여 노년 여성의 기본 주파수가 개선되었을 수 있다.

셋째, Jitter, Shimmer, NHR이 유의하게 낮아졌고 CPPs가 유의 하게 증가하였다. 노화가 진행됨에 따라 성대는 경직되거나 휘어져 비정상적인 형태와 움직임이 나타난다. 이로 인한 음성의 불안정은 성대의 형태와 진동 양상에 영향을 미쳐 주파수변동률, 진폭변동 률, 소음대배음비가 증가한다(Lortie, Thibeault, Guitton, \& Tremblay, 2015). 이는 음량 증가에 초점을 둔 훈련을 통해 개선할 수 있 다. 음량을 증가시키면 성대의 접촉률이 증가하고 이로 인해 기식 성 및 조조성(roughness)의 음질 및 음향학적 지표가 개선된다 (Nam, Rheem, Yun, Cho, \& Choi, 2011). 실제로 노년층을 대상으 로 음량 증가에 초점을 둔 훈련을 실시하게 한 결과, 성대의 휨 정도 가 감소하였고 주파수변동률, 진폭변동률, 소음대배음비가 개선되 었다(Godoy et al., 2019; Lu et al., 2013). 한편 본 연구에서는 선행연 구와 달리 음량이 아닌 음도 증가에 초점을 둔 발성 훈련법을 실시
하였음에도 불구하고 Jitter, Shimmer, NHR이 유의하게 감소하였 다. 이는 훈련받지 않은 일반 성인의 경우 음도를 증가시키면 음량 도 함께 증가하는 경향을 보이므로(Choi, Nam, Kim, Kim, \& Choi, 2006) EPG를 실시하는 동안 음도 뿐만 아니라 음량도 상승되어 나 타난 결과일 수 있다.

또한 본 연구에서는 기식성과 높은 부적 상관관계를 보이는 CPPs (Hillenbrand \& Houde, 1996)도 훈련 후 유의하게 증가하였 다. 본 연구에서 CPPs는 Jitter, Shimmer, NHR과 달리 문단 읽기 자 료를 통해 분석한 음향학적 지표이므로 단모음 연장발성 수준뿐 만 아니라 문단 읽기 수준에서도 노년층의 음질이 개선되었음을 확인할 수 있다. 선행연구에서는 단모음 연장발성 이외에도 문장 및 대화 수준의 문맥에서 훈련이 이루어진 반면, 본 연구에서는 단 모음 연장발성 수준에서만 훈련을 실시하였음에도 불구하고 문단 읽기 수준에서 음질이 개선되었다. 이는 ASSET을 통해 개선된 음 성 기능이 상위 문맥으로 일반화가 이루어졌음을 의미한다.

넷째, NHR의 개선이 훈련 종료 12 주 후까지 유지되었다. 특정 기 능의 개선 및 장기적인 유지를 위해서는 그 기능을 활성화시키는 행동을 반복할 필요가 있으며 이는 고강도의 훈련으로 진행되어야 한다(Kleim \& Jones, 2008; Langhorne, Bernhardt, \& Kwakkel, 2011). 훈련 강도에 대한 명확한 준칙은 없지만 본 연구에서는 8 주 동안(주 5 회, 일 3 회) 총 120 회기의 훈련을 진행하였으며 이는 선행 연구(Langhorne et al., 2011; Roy, 2012)의 훈련 강도와 비교하였을 때 고강도 훈련에 해당한다. 노년층을 대상으로 한 고강도 음성치 료의 장기 치료 효과를 확인한 연구는 없으나 고강도의 훈련은 운 동 피질 내 시냅스의 수를 증가시키고 시냅스 반응의 장기강화작 용(long-term potentiation)을 유발하므로(Kleim \& Jones, 2008) 고강도의 훈련 프로토콜은 $\mathrm{MPT}$ 및 음향학적 지표의 단기적인 개 선 이외에도 NHR의 장기적인 개선 유지에 영향을 미쳤을 것이다. 앞서 언급한 바와 같이 NHR은 성문 간격의 크기에 영향을 받는 음 향학적 지표이므로 NHR의 장기적인 개선 유지는 고강도의 AS$\mathrm{SET}$ 훈련이 노년층의 성문 간격의 크기를 줄이는데 장단기적으로 효과적일 수 있음을 시사한다.

한편 단기 효능이 나타난 변인 중 NHR만 장기적으로 유지되었 는데 이는 평가 시점과 대상자의 연령에 기인한 결과일 수 있다. 장 기 치료 효능은 평가 시점에 따라 그 결과가 다르게 나타날 수 있다. 본 연구에서는 훈련 종료 12 주 후에 추적 평가를 실시하였는데 이 는 선행연구와 비교하였을 때 상대적으로 긴 간격의 평가 시점일 수 있다. 일반적으로 노년층은 노화로 인해 신체 전반의 근육량이 감소하고 근력이 약화되며 이로 인해 치료 후에도 퇴화가 이루어져 젊은 성인에 비해 디트레이닝(detraining) 효과가 크게 나타난다 
(Toraman, 2005). 따라서 노년층을 대상으로 긴 간격의 평가 시점 에서 장기 효능을 측정한다면 그 효능이 감소할 것이다. 이에 따라 본 연구에서는 다양한 변인에서 장기 효능이 나타나지 않았던 것 일 수 있다. 그러나 이와 같이 디트레이닝 효과에 취약한 조건에서 도 NHR의 개선이 장기적으로 유지되었다. 이러한 결과는 NHR이 노인성 음성장애의 주 음성 특성인 기식성을 대표하는 음향학적 지표라는 점에서 의의가 있으며 이는 추후 노년층을 대상으로 디트 레이닝 효과를 확인하는 데 있어 유용한 임상적 근거가 될 수 있다.

다섯째, VHI-10의 총점이 유의하게 낮아졌다. 노인성 음성장애 는 음성 관련 삶의 질을 저하시키고 의사소통이 이루어지는 대부 분의 활동에 지장을 준다(Etter et al., 2019). 노년층을 대상으로 한 선행연구에 따르면 음성치료 후 VRQOL (voice-related quality of life) 등의 음성 관련 삶의 질 평가 점수가 개선되었다(Godoy et al., 2019; Kang \& Yoo, 2019). VHI-10은 음질과 높은 상관관계를 보이 므로 본 연구에서 훈련 후 개선된 MPT 및 음향학적 지표가 노년층 의 음성 관련 삶의 질 개선에도 긍정적 영향을 미쳤을 것이다 (Rosen et al., 2004). 특히 자발화의 특성을 잘 반영할 수 있는 문단 읽기 과제에서의 CPPs 개선은 훈련 후 일상생활에서의 음성 문제 가 개선되었음을 의미할 수 있다.

여섯째, ASSET은 고강도의 훈련으로 인한 음성 과부하를 보상 하여 본 연구 결과에 긍정적 영향을 미쳤을 것이다. 발성 훈련을 실 시하면 필연적으로 음성 부하가 증가할 수 밖에 없으므로 고강도 의 음성치료를 제공하는 데 있어 훈련량(dosage)을 설정하는 것은 매우 중요한 문제이다. 이상적인 훈련량을 넘어서면 성대 조직에 손 상이 발생할 수 있으며 음성 산출에 부작용을 야기할 수 있다(Roy, 2012). 예를 들어 집중적인(intensive) 음성치료로 알려진 LSVT는 4 주 동안(주 4 회, 일 1 회) 총 16 회의 음성치료를 진행하며 1 회기 당 소요시간은 약 40 분(총 640 분 소요)인 반면(Ramig, Pawlas, \& Countryman, 1995), ASSET의 EPG는 8주 동안(주 5회, 일 3회) 총 120 회의 훈련을 진행하며 1 회기 당 소요시간은 약 10 분(총 1200 분 소요)이다. 그러나 훈련 후 부작용은 관찰되지 않았으며 노년층의 음성 기능 개선 및 장기적인 유지가 나타났다. 이러한 결과는 다양 한 요인이 영향을 미쳤을 수 있는데 그 중 하나는 ASSET이 음성 과 부하를 보상할 수 있는 요소를 포함하고 있다는 점이다. ETR을 실 시하는 동안 혀를 내미는 동작은 설근을 인두 밖으로 내보내고 후 두 입구를 개방시킨다(Lindberg-Kransmo, 2002). 이는 EPG 또는 $\mathrm{EPS}$ 를 실시하는 동안 강하게 수축된 후두 근육을 이완시킬 수 있 다. 실제로 혀를 내미는 기법은 Boone, McFarlane, Berg와 Zraick (2019)의 음성 촉진 접근법 중 혀 내밀기 / i/ 과제에서 사용되는 절 차로 후두의 과긴장으로 인해 긴장된 음성을 산출하는 환자에게
유용하게 사용될 수 있다. 따라서 음성 과부하를 보상할 수 있는 훈련 기법은 노년층의 음성 기능 개선 및 장기적 유지에 영향을 미 쳤을 것이다.

일곱째, 모바일 헬스케어 애플리케이션의 도입은 가정 기반 (home-based) 자가 훈련을 통해 나타난 긍정적 연구 결과의 영향 을 미쳤을 것이다. 우선 리마인더 기능은 고강도 반복 훈련의 순응 도를 높이는 데 효과적인 수단이 될 수 있다. 치료를 통한 기능 향 상 및 개선에 핵심적인 역할을 하는 요인 중 하나는 대상자가 치료 계획을 순응하는 것이다. 그러나 치료 비순응은 행동적 치료에 있 어 빈번히 나타나는 문제이며 특히 여러 치료 양식 중 가정 기반 자 가 치료는 가장 높은 수준의 비순응도를 보인다(Campbell et al., 2001). 365 삼킴 건강 코치 앱의 리마인더 기능(예, 훈련 진행 표시 장치, 알람)은 훈련 진행 현황을 파악하기 용이하며 치료 순응도를 높이는 데 효과적이므로 노년층은 이를 통해 고강도의 자가 반복 훈련을 순응할 수 있었을 것이다(Kim, Lee et al., 2020). 이외에도 실시간 음도 그래프, 거울 기능 등의 바이오피드백 시스템은 연구 자나 임상가의 개입 없이 노년층이 올바르게 훈련하는 데 도움을 줄 수 있다. 바이오피드백 시스템은 훈련 목적에 부합하지 않는 방 법, 즉 부적절하거나 부정확한 방법으로 훈련하는 것을 방지한다 (Vose, Marcus, \& Humbert, 2019). 즉, 노년층은 바이오피드백 시 스템을 통해 실시간으로 자신의 수행을 확인함으로써 정확한 방법 으로 훈련할 수 있었을 것이다.

상기의 결과 및 논의점을 종합해보면 ASSET의 세 가지 훈련법 은 후두 근육, 특히 성대 강화에 직간접적으로 영향을 미쳐 노년층 의 음성 기능 및 음성 관련 삶의 질 개선에 효과적이며 모바일 헬스 케어의 도입은 치료 순응도를 높이는 데 긍정적 영향을 미쳤을 것 이다. 본 연구에서 주목할 만한 점은 본 연구의 프로토콜이 한 가지 의 발성 훈련과 두 가지의 비발성 훈련으로 구성되어 있음에도 불 구하고 다양한 발성 훈련을 포함하는 선행연구와 유사한 연구결과 가 나타났다는 것이다. 문화에 따라차이가 있을 수 있지만 가정 기 반의 발성 훈련은 소음 유발 문제로 이어질 수 있으므로 최소한의 발성 훈련으로 최대한의 효율을 이끌어낼 수 있는 프로토콜로 고 안될 필요가 있다. 이와 같은 관점에서 음성에 긍정적으로 영향을 줄 수 있는 비발성 훈련법을 훈련 프로토콜에 도입하는 것은 유용 한 방안일 수 있다. 또한 많은 기법을 다루지 않고 세 가지 기법만 포함한 것은 노년층의 인지적 부담을 줄이는 데 일조함으로써 고강 도의 훈련 프로토콜을 올바르게 수행하는 데 긍정적 영향을 미쳤 을 수 있다. 따라서 ASSET은 노년층을 위한 가정 기반 음성치료로 서 유용하게 사용될 수 있을 것이다.

본 연구의 제한점 및 후속연구를 위한 제언은 다음과 같다. 첫째, 
본 연구는 노년층 7명을 대상으로 훈련 효능을 검증하였다. 일반화 를 위하여 향후 더 많은 노년층을 대상으로 훈련 효능을 검증할 필 요가 있다. 둘째, 본 연구에서는 음성 관련 삶의 질 평가를 추적 평 가 단계에서 실시하지 않았다. 음성 기능 이외에도 음성 관련 삶의 질 개선이 장기적으로 유지될 수 있으나 추적 평가 단계에서 음성 관련 삶의 질 평가를 실시하지 않아 장기 효능을 확인하지 못하였 다. 후속연구에서 추적 평가 시 음성 관련 삶의 질 평가가 이루어진 다면 ASSET이 노년층 음성 관련 삶의 질 개선에 미치는 장기적인 유지 효능을 확인할 수 있을 것이다. 셋째, ASSET은 노년층뿐만 아 니라 신경학적 질환(예, 파킨슨병, 다계통 위축증, 근위축측삭경화 증)으로 인해 음성 기능이 저하되는 환자에게도 효과적일 수 있다. 따라서 향후 연구에서는 음성 기능이 저하된 신경학적 질환자를 대상으로 ASSET을 실시하게 한다면 ASSET이 신경학적 질환자의 음성에 미치는 영향을 확인할 수 있을 것이다. 넷째, ASSET은 말에 도 영향을 줄수 있으므로 말운동장애 환자를 대상으로 연구를 실 시할 경우, 말 명료도와 관련된 음향학적 지표(예, 모음삼각도, 제2 포먼트 기울기) 분석과 말 관련 삶의 질 평가를 실시한다면 말에 미 치는 영향도 확인할 수 있을 것이다.

\section{REFERENCES}

Arakawa, I., Koide, K., Takahashi, M., \& Mizuhashi, F. (2015). Effect of the tongue rotation exercise training on the oral functions in normal adults Part 1 investigation of tongue pressure and labial closure strength. Journal of Oral Rehabilitation, 42(6), 407-413.

Bene, B. A., O’Connor, S., Mastellos, N., Majeed, A., Fadahunsi, K. P., \& O’Donoghue, J. (2019). Impact of mobile health applications on self-management in patients with type 2 diabetes mellitus: protocol of a systematic review. BMJ Open, 9(6), 1-8.

Boersma, P., \& Weenink, B. (2011). Praat: doing phonetics by computer. Ear and Hearing, 32(2), 266.

Boone, D., McFarlane, S., Berg, V. S., \& Zraick, R. (2019). The voice and voice therapy (10th ed.). Pearson.

Bradley, J. P., Hapner, E., \& Johns III, M. M. (2014). What is the optimal treatment for presbyphonia?. The Laryngoscope, 124(11), 2439-2440.

Campbell, R., Evans, M., Tucker, M., Quilty, B., Dieppe, P., \& Donovan, J. L. (2001). Why don't patients do their exercises? understanding non-compliance with physiotherapy in patients with osteoarthritis of the knee. Journal of Epidemiology and Community Health, 55(2), 132-138.

Choi, S. H., Nam, D. H., Kim, D. W., Kim, Y. H., \& Choi, H. S. (2006). Char- acteristics of phonatory and respiratory control on pitch, loudness, register change in untrained and trained singers. Journal of The Korean Society of Laryngology, Phoniatrics and Logopedics, 17(2), 115-126.

Dejonckere, P. H. (2010). Voice evaluation and respiratory function assessment. Otorhinolaryngology, Head and Neck Surgery, 563-574.

Desjardins, M., Halstead, L., Simpson, A., Flume, P., \& Bonilha, H. S. (2020). Respiratory muscle strength training to improve vocal function in patients with presbyphonia. Journal of Voice: Official Journal of The Voice Foundation, [Epub]. https://doi.org/10.1016/j.jvoice.2020.06.006.

Etter, N. M., Hapner, E. R., Barkmeier-Kraemer, J. M., Gartner-Schmidt, J. L., Dressler, E. V., \& Stemple, J. C. (2019). Aging Voice Index (AVI): reliability and validity of a voice quality of life scale for older adults. Journal of Voice: Official Journal of The Voice Foundation, 33(5), 807-e7.

Fabron, E., Silvério, K., Berretin-Felix, G., Andrade, E. C., Salles, P. F., Moreira, P., \& Brasolotto, A. G. (2018). Voice therapy for the elderly with progression of intensity, frequency, and phonation time: case reports. CoDAS, 30(6), e20170224.

Fu, S., Theodoros, D. G., \& Ward, E. C. (2015). Delivery of intensive voice therapy for vocal fold nodules via telepractice: a pilot feasibility and efficacy study. Journal of Voice: Official Journal of The Voice Foundation, 29(6), 696-706.

Fujiki, R. B., Oliver, A. J., Sivasankar, M. P., Craig, B. A., \& Malandraki, G. A. (2019). Secondary voice outcomes of a randomized clinical trial comparing two head/neck strengthening exercises in healthy older adults: a preliminary report. Journal of Speech, Language, and Hearing Research, 62(2), 318-323.

Fujimaki, Y., Tsunoda, K., Kobayashi, R., Tonghyo, C., Tanaka, F., Kuroda, H., ... Research Group for Aspiration Pneumonia, National Hospital Organization, Japan. (2017). Independent exercise for glottal incompetence to improve vocal problems and prevent aspiration pneumonia in the elderly: a randomized controlled trial. Clinical Rehabilitation, 31(8), 1049-1056.

Godoy, J., Silverio, K., \& Brasolotto, A. (2019). Effectiveness of vocal therapy for the elderly when applying conventional and intensive approaches: a randomized clinical trial. Journal of Voice: Official Journal of The Voice Foundation, 33(5), 809-e19.

Gorman, S., Weinrich, B., Lee, L., \& Stemple, J. C. (2008). Aerodynamic changes as a result of vocal function exercises in elderly men. The Laryngoscope, 118(10), 1900-1903.

Griffin, M., Bentley, J., Shanks, J., \& Wood, C. (2018). The effectiveness of Lee Silverman Voice Treatment therapy issued interactively through an 
iPad device: a non-inferiority study. Journal of Telemedicine and Telecare, 24(3), 209-215.

Hari Kumar, K. V., Garg, A., Ajai Chandra, N. S., Singh, S. P., \& Datta, R. (2016). Voice and endocrinology. Indian Journal of Endocrinology and Metabolism, 20(5), 590-594.

Hillenbrand, J., \& Houde, R. A. (1996). Acoustic correlates of breathy vocal quality: dysphonic voices and continuous speech. Journal of Speech and Hearing Research, 39(2), 311-321.

Honda, K., Hirai, H., Masaki, S., \& Shimada, Y. (1999). Role of vertical larynx movement and cervical lordosis in F0 control. Language and Speech,42 (Pt 4), 401-411.

Inamoto, Y., Saitoh, E., Ito, Y., Kagaya, H., Aoyagi, Y., Shibata, S., ..., \& Palmer, J. B. (2018). The Mendelsohn maneuver and its effects on swallowing: kinematic analysis in three dimensions using dynamic area detector CT. Dysphagia,33(4), 419-430.

Kaneko, M., Hirano, S., Tateya, I., Kishimoto, Y., Hiwatashi, N., Fujiu-Kurachi, M., \& Ito, J. (2015). Multidimensional analysis on the effect of vocal function exercises on aged vocal fold atrophy. Journal of Voice: Official Journal of the Voice Foundation, 29(5), 638-644.

Kang, H. N., \& Yoo, J. Y. (2019). A case study of the effects of respiration trainers on vocal aerobic treatment program. Communication Sciences \& Disorders, 24(1), 244-260.

Kang, Y. W. (2006). A normative study of the Korean-Mini Mental State Examination (K-MMSE) in the elderly. The Korean Journal of Psychology: General, 25(2), 1-12.

Kennedy, S., Pisegna, J. M., Kim, K., Parker, L., \& Langmore, S. (2020). The pitch glide speech task lacks clinical utility to infer laryngeal lift during swallowing. International Journal of Speech-Language Pathology, 22(5), 511-516.

Kent, R. D., Vorperian, H. K., Kent, J. F., \& Duffy, J. R. (2003). Voice dysfunction in dysarthria: application of the Multi-Dimensional Voice Program. Journal of Communication Disorders, 36(4), 281-306.

Kim, H. (1996). Perceptual, acoustical, and physiological tools in ataxic dysarthria management: a case report. Proceedings of the 2nd KSPS Conference, 9-22.

Kim, H., Cho, N. B., Kim, J., Kim, K. M., Kang, M., Choi, Y., ..., \& Shin, S. (2020). Implementation of a home-based mhealth app intervention program with human mediation for swallowing tongue pressure strengthening exercises in older adults: longitudinal observational study. JMIR mHealth and uHealth, 8(10), 1-19.
Kim, H., Lee, S. H., Cho, N. B., You, H., Choi, T., \& Kim, J. (2020). User-dependent usability and feasibility of a swallowing training mhealth app for older adults: mixed methods pilot study. JMIR mHealth and uHealth, 8(7), $1-16$.

Kleim, J. A., \& Jones, T. A. (2008). Principles of experience-dependent neural plasticity: implications for rehabilitation after brain damage. Journal of Speech, Language, and Hearing Research, 51(1), S225-S239.

Langhorne, P., Bernhardt, J., \& Kwakkel, G. (2011). Stroke rehabilitation. Lancet, 377(9778), 1693-1702.

Lee, S. J., Lim, S. E., \& Choi, H. S. (2017). A comparison of cepstral and spectral measures according to measurement position in a reading passage. Communication Sciences \& Disorders, 22(4), 818-826.

Lindberg-Kransmo, M. (2002). The influence of the tongue on vocal production (Master's thesis). North Texas University, Denton, Texas, USA.

Lortie, C. L., Thibeault, M., Guitton, M. J., \& Tremblay, P. (2015). Effects of age on the amplitude, frequency and perceived quality of voice. Age, 37(6), $1-24$.

Lu, F. L., Presley, S., \& Lammers, B. (2013). Efficacy of intensive phonatoryrespiratory treatment (LSVT) for presbyphonia: two case reports. Journal of Voice: Official Journal of The Voice Foundation, 27(6), 786-e11.

Mendelsohn, M. S., \& McConnel, F. M. (1987). Function in the pharyngoesophageal segment. The Laryngoscope, 97(4), 483-489.

Miloro, K. V., Pearson Jr, W. G., \& Langmore, S. E. (2014). Effortful pitch glide: a potential new exercise evaluated by dynamic MRI. Journal of Speech, Language, and Hearing Research, 57(4), 1243-1250.

Nam, D. H., Rheem, S. S., Yun, B. R., Cho, S. A., \& Choi, H. S. (2011). Changes in acoustic parameters according to intensity increase in voice assessment. Journal of The Korean Society of Laryngology, Phoniatrics and Logopedics, 22(2), 143-150.

Patel, R. R., Awan, S. N., Barkmeier-Kraemer, J., Courey, M., Deliyski, D., Eadie, T., ..., \& Hillman, R. (2018). Recommended protocols for instrumental assessment of voice: American Speech-Language-Hearing Association expert panel to develop a protocol for instrumental assessment of vocal function. American Journal of Speech-Language Pathology, 27(3), 887-905.

Pessin, A. B., Tavares, E. L., Gramuglia, A. C., de Carvalho, L. R., \& Martins, R. H. (2017). Voice and ageing: clinical, endoscopic and acoustic investigation. Clinical Otolaryngology, 42(2), 330-335.

Pontes, P., Brasolotto, A., \& Behlau, M. (2005). Glottic characteristics and voice complaint in the elderly. Journal of Voice: Official Journal of The 
Voice Foundation, 19(1), 84-94.

Pouderoux, P., \& Kahrilas, P. J. (1995). Deglutitive tongue force modulation by volition, volume, and viscosity in humans. Gastroenterology, 108(5), 1418-1426.

Ramig, L. O., Pawlas, A., \& Countryman, S. (1995). The Lee Silverman Voice Treatment (LSV7): a practical guide to treating the voice and speech disorders in Parkinson disease. Iowa City, IA: University of Iowa, National Center for Voice and Speech.

Rapoport, S. K., Menier, J., \& Grant, N. (2018). Voice changes in the elderly. Otolaryngologic Clinics of North America, 51(4), 759-768.

Rosen, C. A., Lee, A. S., Osborne, J., Zullo, T., \& Murry, T. (2004). Development and validation of the voice handicap index-10. The Laryngoscope, 114(9), 1549-1556.

Rosow, D. E., \& Pan, D. R. (2019). Presbyphonia and minimal glottic insufficiency. Otolaryngologic Clinics of North America, 52(4), 617-625.

Roy, N. (2012). Optimal dose-response relationships in voice therapy. International Journal of Speech-Language Pathology, 14(5), 419-423.

Takano, S., Kimura, M., Nito, T., Imagawa, H., Sakakibara, K., \& Tayama, N. (2010). Clinical analysis of presbylarynx--vocal fold atrophy in elderly in- dividuals. Auris, Nasus, Larynx, 37(4), 461-464.

Toraman, N. F. (2005). Short term and long term detraining: is there any difference between young-old and old people?. British Journal of Sports Medicine, 39(8), 561-564.

Vose, A. K., Marcus, A., \& Humbert, I. (2019). Kinematic visual biofeedback improves accuracy of swallowing maneuver training and accuracy of clinician cues during training in stroke patients with dysphagia. $P M \& R$ : The Journal of Injury, Function, and Rehabilitation, 11(11), 1159-1169.

Wildenbos, G. A., Jaspers, M., Schijven, M. P., \& Dusseljee-Peute, L. W. (2019). Mobile health for older adult patients: using an aging barriers framework to classify usability problems. International Journal of Medical Informatics, 124, 68-77.

Yun, Y. S., Kim, H., Son, Y. I., \& Choi, H. S. (2008). Validation of the Korean Voice Handicap Index (K-VHI) and the clinical usefulness of Korean VHI-10. Communication Sciences \& Disorders, 13(2), 216-241.

Ziegler, A., Verdolini Abbott, K., Johns, M., Klein, A., \& Hapner, E. R. (2014). Preliminary data on two voice therapy interventions in the treatment of presbyphonia. The Laryngoscope, 124(8), 1869-1876. 


\section{국문초록}

\section{모바일 헬스케어 애플리케이션을 이용한 구강 및 인후두 근력 강화 훈련이 노년 여성의 음성에 미치는 장단기 효능} 조남빈 ${ }^{1} \cdot$ 조성래 ${ }^{2} \cdot$ 최성희 ${ }^{3} \cdot$ 유희천 ${ }^{4} \cdot$ 남석인 $^{5} \cdot$ 김향희 ${ }^{12}$

${ }^{1}$ 연세대학교 대학원 언어병리학협동과정, ${ }^{2}$ 연세대학교 의과대학 재활의학교실, ${ }^{3}$ 대구가톨릭대학교 바이오메디대학 언어청각치료학과, ${ }^{4}$ 포항공과대학교 산업경영공학과, ${ }^{5}$ 연세대학교 사회복지대학원

배경 및 목적: 노화로 인한 음성 기능의 저하는 의사소통과 일상생활을 방해하며 삶의 질에 부정적 영향을 미치므로 노인성 음성장애 에 대한 중재가 필요하다. 치료 효과를 최대화하기 위해서는 치료 순응이 필수적이며 모바일 헬스케어는 순응도를 높이는 데 효과적일 수 있다. 이 연구에서는 애플리케이션을 이용한 구강 및 인후두 근력 강화 훈련이 노년층의 음성에 미치는 효과를 확인하고자 한다. 방 법: 11명의 노인을 대상으로 8주 동안 가정에서 애플리케이션을 이용하여 ASSET (A Successful Swallowing with Effortful Training)을 실시하게 하였다. 이 중 프로토콜을 적합하게 수행한 7명(여성 7명, 평균 연령 74.6 5 5.7세)을 대상으로 치료 효과를 확인하였으며 효과 성 측정은 음성 기능 평가와 음성 관련 설문평가를 통해 이루어졌다. 결과: 음성 기능 평가 결과, 훈련 직후 $\mathrm{MPT}, \mathrm{F} 0, \mathrm{CPPs}$ 가 유의하게 증가하였고 Jitter, Shimmer, NHR이 유의하게 감소하였으며 NHR의 개선이 훈련 종료 12주 후에도 유지되고 있었다. 음성 관련 설문평 가 결과, 훈련 직후 VHI-10 총점이 유의하게 감소하였다. 논의 및 결론: 애플리케이션을 이용한 구강 및 인후두 근력 강화 훈련 후 노년 여성의 음성 기능 및 음성 관련 삶의 질이 개선되었으며 음성 기능의 개선이 장기적으로 유지되었다. 본 훈련 프로토콜은 노인성 음성 장애의 효과적인 음성치료로 사용될 수 있을 것이다.

핵심어: 노화, 노인성 음성장애, 구강 및 인후두 근력 강화 훈련, 모바일 헬스케어

이 논문은 정부(과학기술통신부)의 재원으로 한국연구재단-과학기술인문융합연구사업의 지원을 받아 수행된 연구임(2020M3C1B6113677, 2020M3C1B6113680).

본 논문은 제 1 저자의 연세대학교 석사학위논문을 발췌 및 수정한 것이며, 일부 내용은 2020 년 ASHA 학술대회 프로그램 위원회에서 발표 승인되었음.

\section{참고문헌}

강연욱 (2006). K-MMSE (Korean-Mini Mental State Examination)의 노인 규준 연구. 한국심리학회지: 일반, 25(2), 1-12.

강하늘, 유재연 (2019). 호흡훈련기를 활용한 성대에어로빅치료 프로그램의 음성개선 효과 사례연구. Communication Sciences \& Disorders, 24(1),

244-260.

김향희 (1996). 운동실조형 마비성구음장애에 적용되는 지각적, 음향학적, 생리학적 도구에 관하여 - 환자사례를 중심으로. 대한음성학회 학술대회, 9-22. 남도현, 임성수, 윤보람, 조선아, 최홍식 (2011). 음성질환자의 음성검사 시 강도 증가에 따른 음향학적 지표의 변화. 대한후두음성언어의학회, 22(2),

143-150.

이승진, 임성은, 최홍식 (2017). 문단 내 위치에 따른 켑스트럼 및 스펙트럼 측정치 비교. Communication Sciences \& Disorders, 22(4), 818-826. 윤영선, 김향희, 손영익, 최홍식 (2008). 한국어판음성장애지수(Voice Handicap Index, VHI)의 타당도 및 VHI-10의 임상적 유용성. Communication Sciences \& Disorders, 13(2), 216-241.

최성희, 남도현, 김더원, 김영호, 최홍식 (2006). 성악가와 훈련 받지 않은 일반인의 음도, 강도, 성구 변화 시 발성 및 호흡조절 특성. 대한후두음성언어 의학회, 17(2), 115-126.

\section{ORCID}

조남빈(제1저자, 대학원생 https://orcid.org/0000-0002-8721-484X); 조성래(공동저자, 교수 https://orcid.org/0000-0003-1429-2684); 최성희(공동저자, 교수 https://orcid.org/0000-0003-2365-6187); 유희천(공동저자, 교수 https://orcid.org/0000-0002-1914-5774); 남석인(공동저자, 교수 https://orcid.org/0000-0001-8053-0690); 김향희(교신저자, 교수 https://orcid.org/0000-0003-4949-2512) 